\title{
ANTI-SOLVENT SONOCRYSTALLISATION OF LACTOSE
}

\author{
Sanjaykumar R. Patel, Z. V. P. Murthy ${ }^{*}$ \\ Chemical Engineering Department, S.V. National Institute of Technology, \\ Surat - 395 007, Gujarat, India
}

\begin{abstract}
The present work deals with ultrasound assisted crystallisation of lactose from lactose solution. The crystallisation of lactose was completed rapidly by applying the ultrasound waves in the presence of an anti-solvent (n-propanol), at the room temperature $\left(30 \pm 3^{\circ} \mathrm{C}\right)$. The yield of lactose was found to be more than $85 \%(\mathrm{w} / \mathrm{w})$ in 4 minutes of sonication. The spread of the crystal size distribution was found to decrease with increase in sonication time.
\end{abstract}

Keywords: lactose recovery, anti-solvent, sonocrystallisation, n-propanol

\section{INTRODUCTION}

Whey is a by-product of dairy industry and its disposal to sewage without treatment causes serious pollution problems. The presence of lactose in whey contributes to its high biochemical oxygen demand (BOD). Recent environmental regulations do not allow whey to be discharged into water bodies because of the presence of lactose. The presence of lactose in whey creates a major pollution problem for dairy industries. Simultaneously, there is an increasing demand for high quality crystalline lactose in the market. Recovery of lactose will resolve, to some extent, the issue of high biochemical oxygen demand (BOD) in effluent streams.

Lactose can be recovered from whey by various processes such as membrane separation, crystallisation, anti-solvent crystallisation, anti-solvent sonocrystallisation, etc. Membrane separation processes are the best to achieve maximum yield (70-100\%) of lactose from whey but high capital and recurring costs with limited membrane life make these processes uneconomical for small and medium scale dairy based product manufacturers (Bund and Pandit, 2007a; Chollangi and Hossain, 2007). Lactose has been recovered from whey for many years by crystallisation, which yields $50-60 \%$ lactose. The problem in lactose crystallisation is that it has a long induction time and large metastable zone width as well as high evaporation costs, which make the process uneconomical. Anti-solvent crystallisation of lactose has been studied with anti-solvents such as methanol (Leviton, 1949) and dimethyl sufoxide (Dincer et al., 1999). However, poor mixing leads to uneven growth of crystals and causes variation in size and shape of crystals (Dhumal et al., 2009). Recently, attempts have been made to develop an anti-solvent crystallisation process with the help of ultrasound waves for lactose recovery and it was found that more than $80 \%(\mathrm{w} / \mathrm{w})$ of lactose crystals could be recovered in 2 to 4 minutes of sonication time (Bund and Pandit, 2007a,b; Patel and Murthy, 2009).

Crystallisation in the presence of ultrasonic waves exhibits a number of specific features, which clearly distinguishes it from conventional crystallisation. Such features include: (a) rapid primary nucleation, which is uniform thorough sonication volumes; (b) easy nucleation in materials which are difficult to nucleate; (c) initiation of secondary nucleation; and (d) production of small and pure crystals with a

*Corresponding author, e-mail: zvpm2000@yahoo.com, zvpm@ched.svnit.ac.in 
uniform size ( De Castro and Priego-Capote, 2006). Dr. Povey's group (Chow et al., 2003) has broadly studied the effect of high intensity ultrasound in sucrose solutions on nucleation phenomena of ice. They showed that the use of high intensity ultrasound can modify the primary and secondary nucleation of ice. The use of ultrasound in anti-solvent crystallisation processes reduces the induction times of nucleation as well as narrows the metastable zone. Ultrasonic vibration and cavitation in the liquid enhances the mixing nature of the solute and solvent uniformly and speedily. The shock wave and microjet produced from the collapse of cavitation bubbles at high pressure and temperature, accelerates the motion of molecules of the liquid and increases molecular impacts. This cavitation phenomenon serves as a means of generating nuclei due to high local supersaturation condition to form new crystals and their growth (Patil et al., 2008). Parameters which affect the primary nucleation under sonication are frequency, physical properties of the liquid and intensity of irradiation (Gogate et al., 2006).

In previous studies (Bund and Pandit, 2007a; Patel and Murthy, 2009), lactose yield in anti-solvent sonocrystallisation with ethanol and acetone was found to be dependent on the solubility of lactose (locally) in the solvents. It is reported (Fernando et al., 2007) that the solubility of lactose increases with temperature and decreases with the carbon chain length of alcohol. Lactose crystal formation will occur differently when one of the solvents is changed, which may provide information to improve the industrial productivity of lactose. Hence, in the present work, we studied the effect of sonocrystallisation parameters on lactose yield with n-propanol as an anti-solvent. The effect of sonication time on lactose crystal size distribution (CSD) was not reported previously. Therefore, it is required to study CSD of lactose in sonocrystallisation with time. Whey contains varying amounts of lactose, proteins and its levels of $\mathrm{pH}$ also vary. Therefore, it is required to study ultrasound assisted crystallisation of lactose in lactose solutions with different parameters such as $\mathrm{pH}(2.9 \pm 0.1$ and $4.2 \pm 0.1)$, lactose concentrations $(16 \% \mathrm{w} / \mathrm{v})$, and protein concentrations $(0.2-0.8 \% \mathrm{w} / \mathrm{v})$. The $\mathrm{pH}$ of the sample was varied by adding $0.1 \mathrm{~N} \mathrm{HCl}$ and sonication was applied for 4 minutes in $16 \%(\mathrm{w} / \mathrm{v})$ lactose solution with $85 \%(\mathrm{v} / \mathrm{v})$ n-propanol concentration.

\section{EXPERIMENTAL}

\subsection{Materials and method}

The ultrasound assisted crystallisation experiments were carried out in an ultrasound bath of $120 \mathrm{~W}$ power, $20 \mathrm{kHz}$ frequency and surface area of $225 \mathrm{~cm}^{2}$ (Aqua Scientific Instruments, Surat, India) using reconstituted lactose solutions. The reconstituted solution was prepared by taking lactose monohydrate (Finar Chemicals, Ahmedabad, India) in distilled water. The n-propanol (Finar Chemicals, Ahmedabad, India) was used as an anti-solvent. A $20 \mathrm{~mL}$ of sample was taken in a $250 \mathrm{~mL}$ round bottom flask and then it was immersed in an ultrasonic bath filled with water and temperature was kept at $30 \pm 3^{\circ} \mathrm{C}$ for each of the experiments during sonocrystallisation. A typical composition of actual concentrated whey contains $12-20 \% \mathrm{w} / \mathrm{v}$ lactose, 0.2- 0.6\% w/v protein and 3.0-5.5 pH (Bund and Pandit, 2007a). Hence, lactose concentration varied from $12-18 \%(\mathrm{w} / \mathrm{v})$ keeping $85 \%(\mathrm{v} / \mathrm{v}) \mathrm{n}$-propanol concentration and 4 minutes sonication time constant. The n-propanol concentration varied from $80-95 \%(\mathrm{v} / \mathrm{v})$ to study its effect. The sonication time varied from $2-8$ minutes in $16 \%(\mathrm{w} / \mathrm{w})$ lactose solution with n-propanol concentration of $85 \%(\mathrm{v} / \mathrm{v})$. The major proteins in actual whey are milk globular proteins, $\alpha$ lactalbumin and $\beta$-lactoglobulin. In the experiments, bovine albumin fraction-V (Himedia Laboratory, Mumbai, India) was used instead of whey protein. The protein concentration varied from $0.2-0.8 \%$ $(\mathrm{w} / \mathrm{v})$ in $16 \%(\mathrm{w} / \mathrm{w})$ lactose solution with $85 \%(\mathrm{v} / \mathrm{v}) \mathrm{n}$-propanol concentration. Lactose crystals at the end of each experiment were separated by vacuum filtration and were dried in vacuum oven at $60^{\circ} \mathrm{C}$ for $2 \mathrm{~h}$. The yield of lactose was calculated based on the initial content of lactose in reconstituted solution used in the flask. All the experiments were carried out in duplicate and graphs were plotted using mean values. Photographs of lactose crystals were captured using a digital camera attached to the microscope 
and observed at 40X magnification (Coslab Laboratory, Ambala Cantt, Haryana, India). About 80 crystals were analysed manually by image analysis software (Coslab Laboratory, Ambala Cantt, Haryana, India) and their perimeter $(P)$, width $(W)$, length $(L)$, and area $(A)$ were measured for each sample. Shape descriptors including shape factor $\left[\left(\begin{array}{ll}4 \pi & A\end{array}\right) / P^{2}\right]$ and elongation ratio $(L / W)$ were calculated. For crystal size distribution (CSD), graphs of the percentage of crystals lying in a particular size range from the total number of crystals observed under the microscope (percentage crystals) vs. average crystal diameter were plotted.

\subsection{Crystallisation kinetics}

The sonocrystallisation kinetics of lactose obtained from lactose solution with different sonication time (120 - $480 \mathrm{~s})$ has been studied using mixed suspension mixed product recovery (MSMPR) model. The growth rate expression (Mullin, 2001) is as follows:

$$
N=N_{0} \exp \left(\frac{-d}{G t}\right)
$$

where, $N=$ number of crystals $\left[\mathrm{mL}^{-1}\right], N_{0}=$ number of embryo size crystals $\left[\mathrm{mL}^{-1}\right], d=$ mean particle diameter $[\mu \mathrm{m}], G=$ growth rate of crystal $\left[\mu \mathrm{m}^{-1}\right]$ and $t=$ crystallisation time $[\mathrm{s}]$. The average roundness factor of the samples at a specified crystallisation time were estimated in the range 0.62-0.69 by image analysis software and the total number of crystals per $\mathrm{mL}(N)$ at the end of crystallisation time (2-8 minutes) was calculated using average roundness, density of lactose and mean diameter of recovered lactose. The mean diameter of lactose was obtained from back scattering data analysed by Turbiscan for each sample. The growth rate of crystal $(G)$ over crystallisation time $(s)$ was calculated by plotting $\ln (N)$ vs. $d$.

\subsection{Determination of mean diameter of lactose crystals using Turbiscan}

The Turbiscan scans a sample with infrared light in a glass tube from top to bottom and measures the percentage of light backscattered from the sample as a function of time. For scanning, precipitated lactose solutions recovered at the end of 2-8 minutes of sonication time were taken in a borosilicate glass tube of 55-60 mm height having $12 \mathrm{~mm}$ inner diameter attached with teflon and rubber stoppers and analysed for the percentage backscattering profiles by light rays of $880 \mathrm{~nm}$ wavelength using Turbiscan classic MA 2000 (Formulaction, France) at a room temperature for 20 minutes. To calculate the migration rate, backscattering data between $20-60 \mathrm{~mm}$ tube heights were selected to compute the slope. This slope was imported to the migration software to calculate the migration rate directly. From the migration rate the mean diameter was calculated based on Stokes law applying the required values as shown in Table 1. Stokes law (Mullin, 2001) is represented by:

$$
d=\sqrt{\frac{V \times 18 \eta}{g \times \Delta Q}}
$$

where: $V$ - the particle migration velocity $\left[\mathrm{cm} \mathrm{s}^{-1}\right], \eta$ - continuous phase viscosity [cP], $\Delta Q$ - the density difference between two phases $\left[\mathrm{g} \mathrm{cm}^{-3}\right], g$ - the gravitational acceleration $\left[\mathrm{cm}^{-2}{ }^{-2}\right], d$ - the diameter of the particle $[\mu \mathrm{m}]$. Particle velocity in sedimentation depends upon the size of the particles, difference between their density, the viscosity and density differences of the liquid. Viscosity of continuous phase was measured by Oswald Viscometer at different temperatures as shown in Table 1. Dispersed phase density of lactose was taken $1.54 \mathrm{~g} \mathrm{~cm}^{-3}$. 
Table 1. Data of lactose crystals in n-propanol-water mixture

\begin{tabular}{|c|c|c|}
\hline $\begin{array}{c}\text { Temperature due to sonication } \\
\text { with respect to time 2-8 minutes } \\
\text { in K }\end{array}$ & $\begin{array}{c}\text { Continuous phase viscosity [cP] } \\
\text { (n-propanol + water) }\end{array}$ & $\begin{array}{c}\text { Continuous phase density } \\
{\left[\mathrm{g}^{-3} \text { cm }\right.}\end{array}$ \\
\hline 304 & 2.14 & 0.8137 \\
\hline 305 & 2.07 & 0.8127 \\
\hline 306 & 2.06 & 0.8117 \\
\hline 307 & 1.91 & 0.8107 \\
\hline
\end{tabular}

\section{EXPERIMENTAL}

\subsection{Effect of sonication time on lactose yield}

The effect of sonication time (2-8 minutes) on lactose yield was studied for samples at different $\mathrm{pH}$ and protein content in 16\% (w/v) lactose solution (Fig. 1). It can be seen from Fig. 1 that the lactose yield was found to increase with increase in sonication time from $2-8$ minutes. The maximum lactose yield was found to be $83.9,83.2$ and $81 \%(\mathrm{w} / \mathrm{w})$ for the samples sonicated at $\mathrm{pH} 4.2,2.9$ and 2.9 with $0.4 \%$ $(\mathrm{w} / \mathrm{v})$ protein concentration, respectively, at 8 minutes of sonication time. It was observed that the lactose yield decreased with an increase in the protein concentration in lactose solution. It is known that at a short sonication time, the ultrasound waves fail to blend the solution and precipitate a little after sonication; at longer sonication time, more crystals precipitate at once but the average size of crystals becomes smaller with continuous sonication (De Castro and Priego-Capote, 2007). When the liquid medium (lactose solution) is exposed to ultrasound waves, alternating compression and expansion cycles are created. A pressure change during these cycles will cause cavitation to occur, and bubbles are formed in the liquid medium. Many of these bubbles will collapse, producing a shock wave, which creates nucleation sites. These nuclei within the crystallisation slurry enhance secondary nucleation due to the presence of crystals (Bund and Pandit, 2007a). Cavitation improves the rate of micromixing of solute (lactose) to solvent (n-propanol), hence, generates many locations of supersaturation, and at the same time increases the nucleation rate. The incidence of micro-streaming enhances heat and mass transfer of solute on the growing crystal, thus increases the yield of lactose (Patel and Murthy, 2009). It can be seen from Fig. 1 that after some sonication time lactose yield attains saturation level. This might be due to a decrease of supersaturation level under continuous sonication in the formation of nuclei and it becomes very low for long sonication time.

\subsection{Effect of anti-solvent on lactose yield}

To study the effect of anti-solvent on the yield of lactose, the concentration of n-propanol as an antisolvent varied from $80-95 \%(\mathrm{v} / \mathrm{v})$ in samples with sonication of 4 minutes in $16 \%(\mathrm{w} / \mathrm{v})$ lactose solutions. Lactose yields of $65.18-98.50 \%(\mathrm{w} / \mathrm{w})$ were obtained with n-propanol concentrations of 80 95\% (v/v), respectively (Fig. 2). It can be observed from Fig. 2 that the highest lactose yield was found at $95 \%(\mathrm{v} / \mathrm{v})$ of n-propanol concentration. Acoustic streaming and microstreaming enhance rapid and uniform mixing of n-propanol and lactose solution which in turn decreases the solubility of lactose in the solvent. Also, the sonication power accelerates mass transfer of solute (lactose) to the surface of growing crystals in the mixture, which leads to a higher recovery of lactose (Patel and Murthy, 2009). 


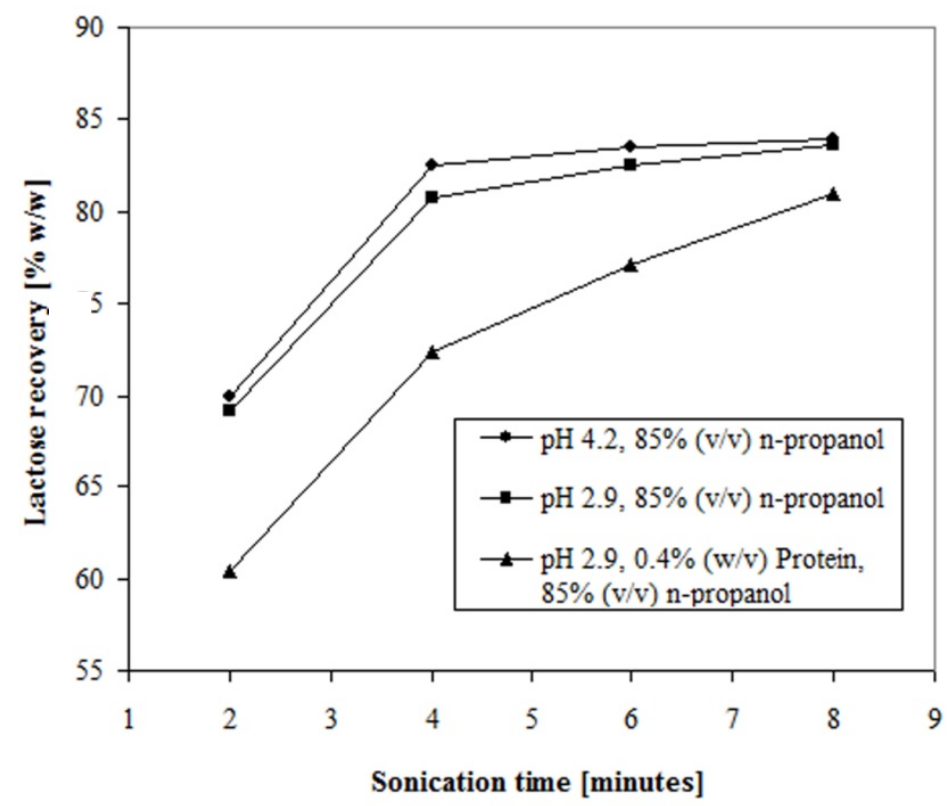

Fig. 1. Effect of sonication time on lactose recovery

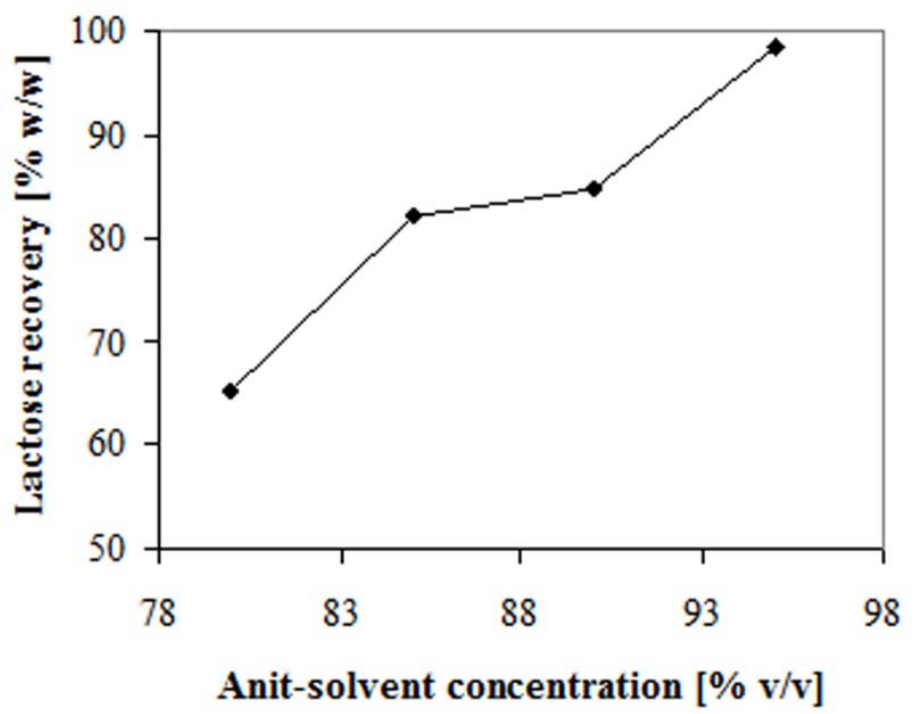

Fig. 2. Effect of anti-solvent on lactose recovery

\subsection{Effect of lactose concentration on lactose yield}

The concentration of lactose varied from $12-18 \%(\mathrm{w} / \mathrm{v})$ with $\mathrm{pH} 4.2,2.9$ and $0.4 \%(\mathrm{w} / \mathrm{v})$ protein as shown in Fig. 3. The lactose yield was observed to increase with an increase in concentration of lactose in samples as shown in Fig. 3. The highest yield was found to be $83.20 \%(\mathrm{w} / \mathrm{w})$ in $18 \%(\mathrm{w} / \mathrm{v})$ lactose concentration at $\mathrm{pH}$ 4.2. It can be observed from Fig. 3 that the yield of lactose sample sonicated at $\mathrm{pH}$ 2.9 and $0.4 \%(\mathrm{w} / \mathrm{v})$ protein is found to be lower in comparison with that of the sample sonicated at $\mathrm{pH}$ 4.2. It is reported that a higher yield of lactose at high initial lactose concentration is due to rapid supersaturation generated by cavitational events which lead to spontaneous nucleation (Bund and Pandit, 2007a; Patel and Murthy, 2009). 


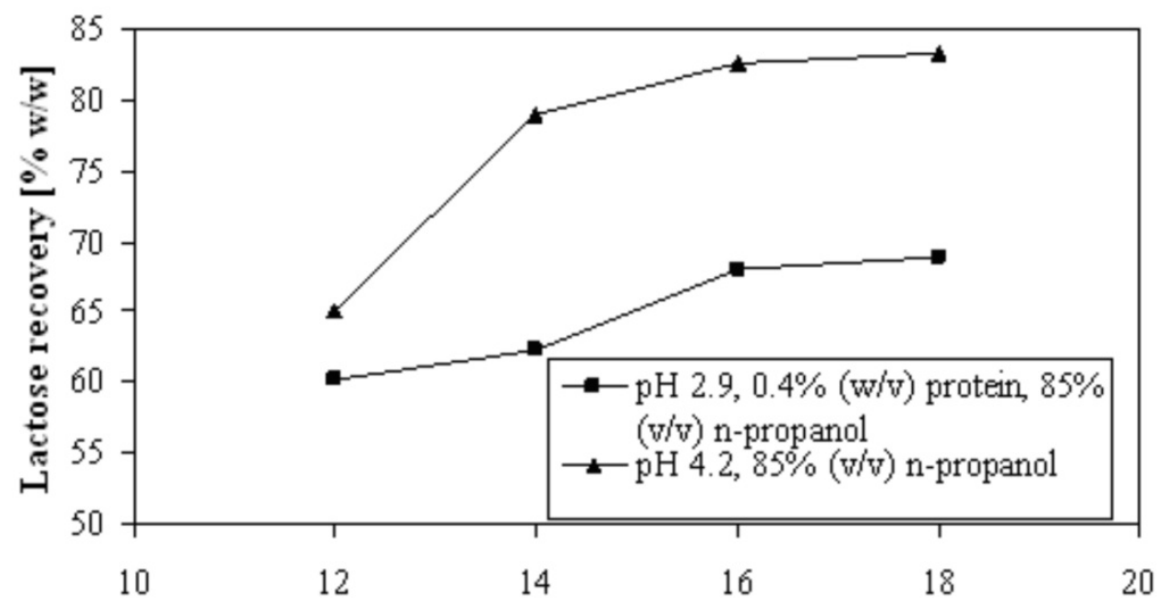

Fig. 3. Effect of lactose concentration on lactose recovery

\subsection{Effect of protein concentration on lactose yield}

It can be observed from Fig. 4 that protein content and $\mathrm{pH}$ of lactose solution were found to be the influencing parameters on lactose yield. The yield of lactose in the samples was found to decrease with an increase in the protein concentration from $0.2-0.8 \%(\mathrm{w} / \mathrm{v})$. Proteins are normally considered as inhibitors of crystallisation. It was also observed that a decrease in lactose yield was almost steady at both the $\mathrm{pH}$ values and higher lactose yield was found for the samples sonicated at $\mathrm{pH}$ 4.2. In a previous study the lactose yield obtained from $13.5 \%(\mathrm{w} / \mathrm{v})$ lactose solution with $85 \%(\mathrm{v} / \mathrm{v})$ ethanol concentration for $\mathrm{pH} 2.8$, markedly decreased whereas for $\mathrm{pH} 4.2$, a gradual decrease was observed with an increase in protein content from $0 \%$ to $0.2 \%$ (Bund and Pandit, 2007a). In another study, lactose yield was found to be increasing with a decrease in $\mathrm{pH}$ from $16 \%(\mathrm{w} / \mathrm{v})$ lactose concentration without protein content and acetone as an anti-solvent (Patel and Murthy, 2009). It is reported that the use of sonication in whey protein concentrate solutions does not appear to change the protein structure to a significant degree, which can influence the functional properties of dairy systems during processing (Jayani et al., 2011).

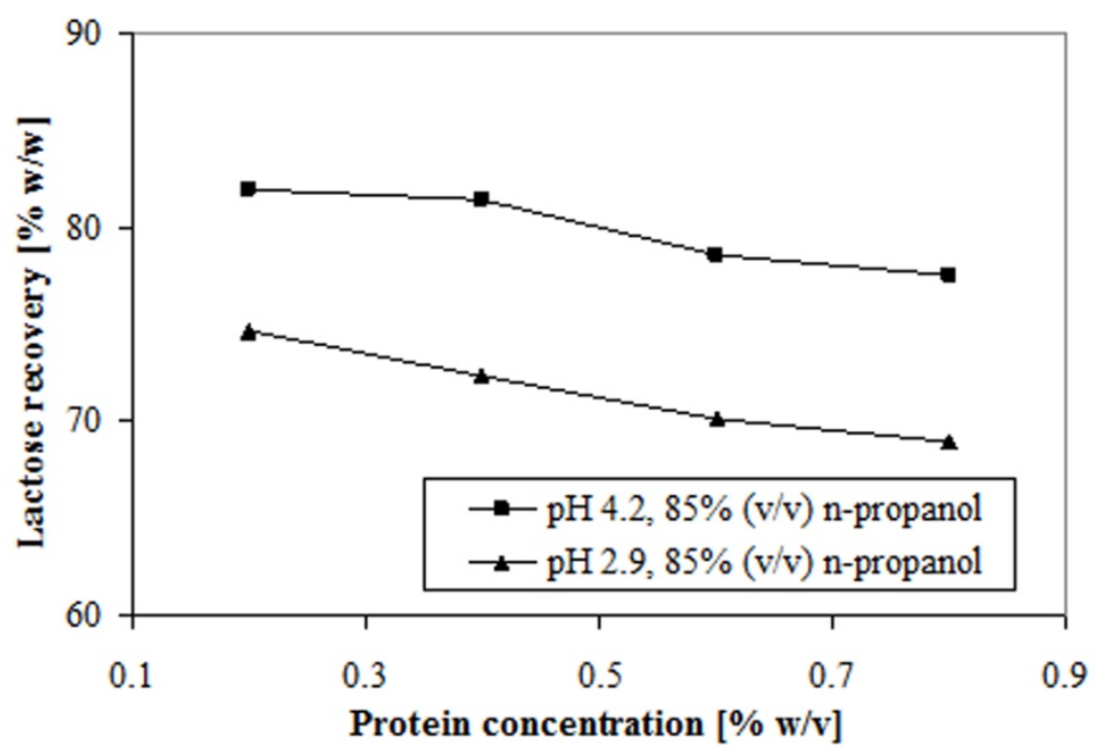

Fig. 4. Effect of protein concentration on lactose recovery 


\subsection{Sonocrystallisation kinetics by Turbiscan}

The Turbiscan optical analyser estimates sedimentation behavior of particles in a glass tube. The back scattering (BS) values of a sample present two rapid variations at the top (liquid / air interface) and bottom (plug of the cell) of a glass tube and between these two zones, there is sedimentation of particles and it presents a constant value of back scattering. Lactose obtained from the lactose solution with concentration of $16 \% \mathrm{w} / \mathrm{v}$ was studied for determining the crystallisation growth under sonocrystallisation process in the presence of n-propanol as an anti-solvent and at different time interval. Back scattering profiles for sonicated samples obtained by Turbiscan are shown in Fig.5 and delta backscattering data are shown in Fig. 6 to study mean value kinetics. Fig. 5 shows the change in percentage of backscattering data along the height of the glass tube with respect to scanning time of the sample (20 minutes) in Turbiscan. It was observed that an increase in sonication time decreased the BS value. The change in the BS shows variation of particle size according to the following relations (Azema, 2006):

$$
B S=\frac{1}{\lambda^{\frac{1}{2}}}
$$

and

$$
\lambda(d, \phi)=\frac{2 d}{\left[3 \phi\left(1-g_{s}\right) Q_{s}\right]^{2}}
$$

where: $B S$ - diffuse reflectance at $135^{\circ}$ detector [\%], $\lambda$ - the photon transport length $[\mu \mathrm{m}], d$ - mean particle diameter $[\mu \mathrm{m}], g_{s}$ - optical parameter in theory of Lorenz-Mie, $Q_{s}$ - optical parameter in theory of Lorenz-Mie, and $\Phi$ - the particle volume fraction [\%].
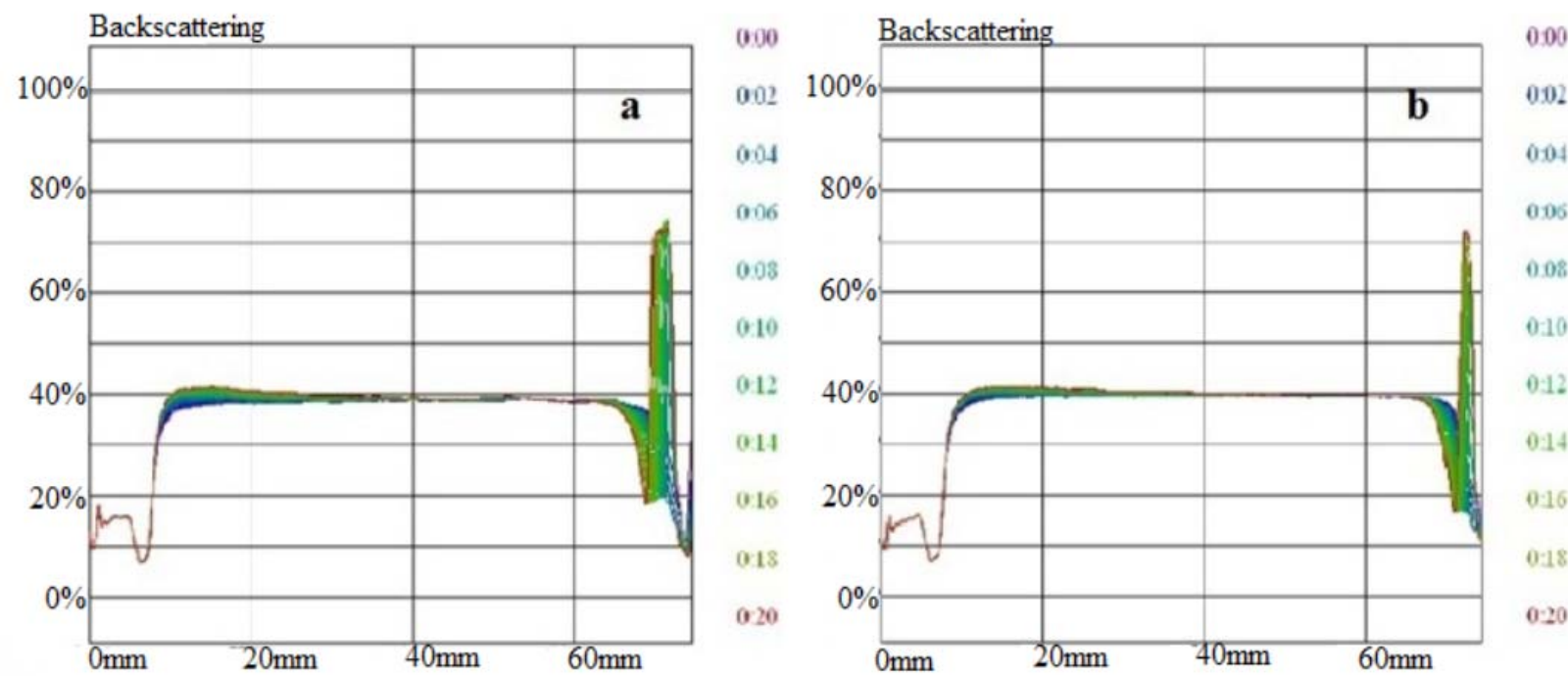

Fig. 5. Backscattering profile of sample; (a) 2 minutes sonication, (b) 4 minutes sonication

According to Eq. (4), the mean values of BS percentage decreased with an increase in sonication time as shown in Fig. 6, which shows that particle size decreases with an increase in sonication time. The mean value of lactose crystals size as obtained by turbiscan using migration software for each sample at specified conditions and growth rate of crystals as calculated using MSMPR model are shown in Table 2. It can be observed from Fig. 7 that the number of crystals per $\mathrm{mL}(N)$ increases with a decrease in mean crystal diameter as sonication time increases leads to a negative slope. This indicates that the available supersaturation used is preferential for the formation of more nuclei under the long 
continuous sonication. Crystal growth for the sample of lactose content $16 \% \mathrm{w} / \mathrm{v}$ with sonication in $85 \%(\mathrm{v} / \mathrm{v}) \mathrm{n}$-propanol concentration was found to be $0.027-0.007 \mu \mathrm{ms}^{-1}$ with respect to the time $120-$ $480 \mathrm{~s}$.

Table 2. Crystallisation growth rate for lactose recovered from reconstituted lactose solution

\begin{tabular}{|c|c|c|c|}
\hline $\begin{array}{c}\text { Sample } \\
\text { sonication time }[\mathrm{s}]\end{array}$ & $\begin{array}{c}\text { Mean diameter } \\
{[\mu \mathrm{m}]}\end{array}$ & $\begin{array}{c}\text { Growth rate } G \\
{\left[\mu \mathrm{m}^{-1}\right]}\end{array}$ & $\begin{array}{c}N_{o} \\
{\left[\text { Number of embryo crystal } \mathrm{mL}^{-1}\right]}\end{array}$ \\
\hline 120 & 15.27 & 0.027 & \multirow{2}{*}{$4.14 \times 10^{8}$} \\
\hline 240 & 13.77 & 0.014 & \\
\hline 360 & 12.22 & 0.009 & \\
\hline 480 & 12 & 0.007 & \\
\hline
\end{tabular}

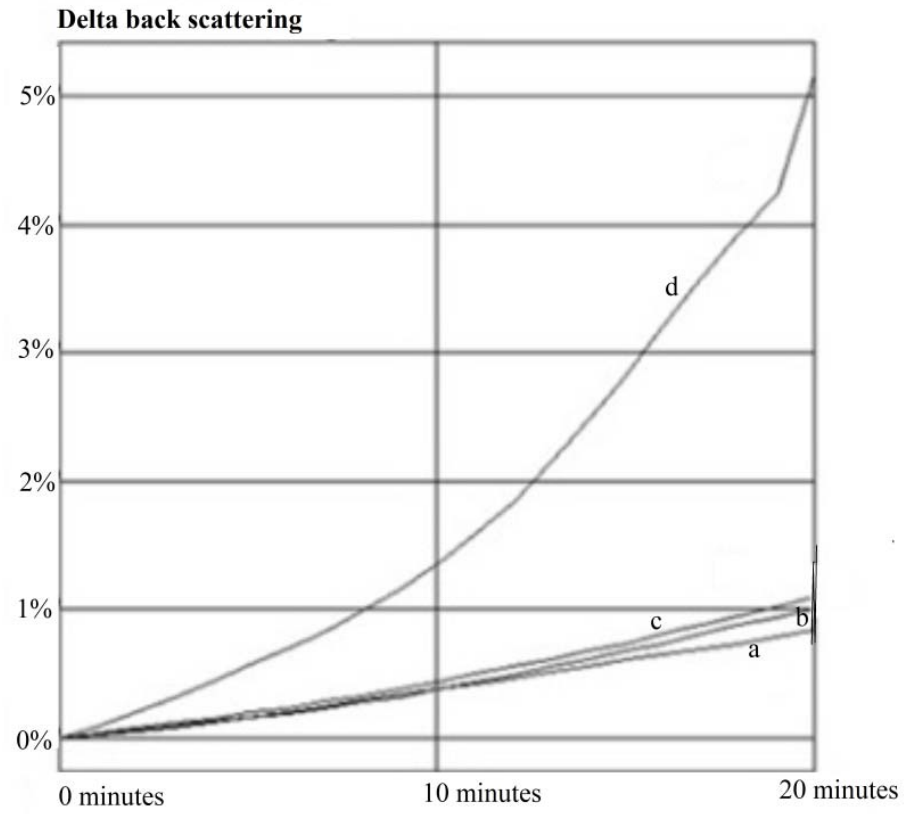

Fig. 6. Delta backscattering data of sample sonicated at: (a) 2 minutes, (b) 4 minutes, (a) 6 minutes, (b) 8 minutes

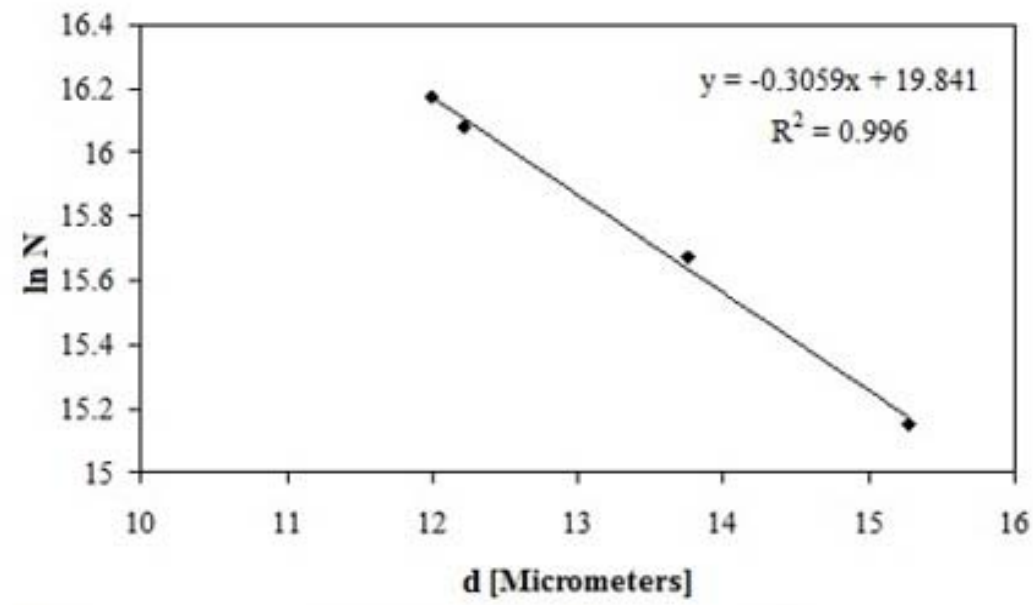

Fig. 7. Plots of $d$ (diameter of crystals) vs. $\ln \mathrm{N}$ [ln (number of crystals recovered/mL)] 


\subsection{Crystal size distribution by image analysis}

Photographs of lactose crystals were obtained at the end of 2-8 minutes of sonication time by a digital camera attached to the microscope at 40X magnifications and are shown in Fig. 8. It can be seen from the photographs (Fig. 8) that the resultant morphology of recovered lactose crystals was found to have a $\mathrm{rod} /$ needle like shape. Crystal size distribution (CSD) and the shape characteristics of lactose were observed to be influenced by sonication time (Fig. 9). The spread of CSD was found to decrease with an increase in sonication time. The average projected area of lactose crystals was observed to be 10.44 , $8.90,6.23$ and $5.92 \mu \mathrm{m}^{2}$ with respect to sonication time of $2,4,6$, and 8 minutes, respectively, in $16 \%$ $(\mathrm{w} / \mathrm{v})$ lactose concentration (Table 3$)$. The average diameters of lactose crystals (Table 3) obtained from lactose solution were found to be smaller in comparison with the conventional lactose sample $(4.02 \mu \mathrm{m})$. Continuous sonication of solutions, in which crystals have already grown, creates secondary nucleation, resulting from cavitationally induced disturbances at the crystal surface and inhibit crystal growth, which results in smaller crystal size. Also, breakage of already grown crystals which started under continuous sonication (Patil et al., 2008). Dr. Povey's group (Chow et al., 2003) showed that the fragmentation of ice dendrites growing in a sucrose solution due to the collapse of bubble was responsible for producing smaller new ice crystals (secondary nucleation).
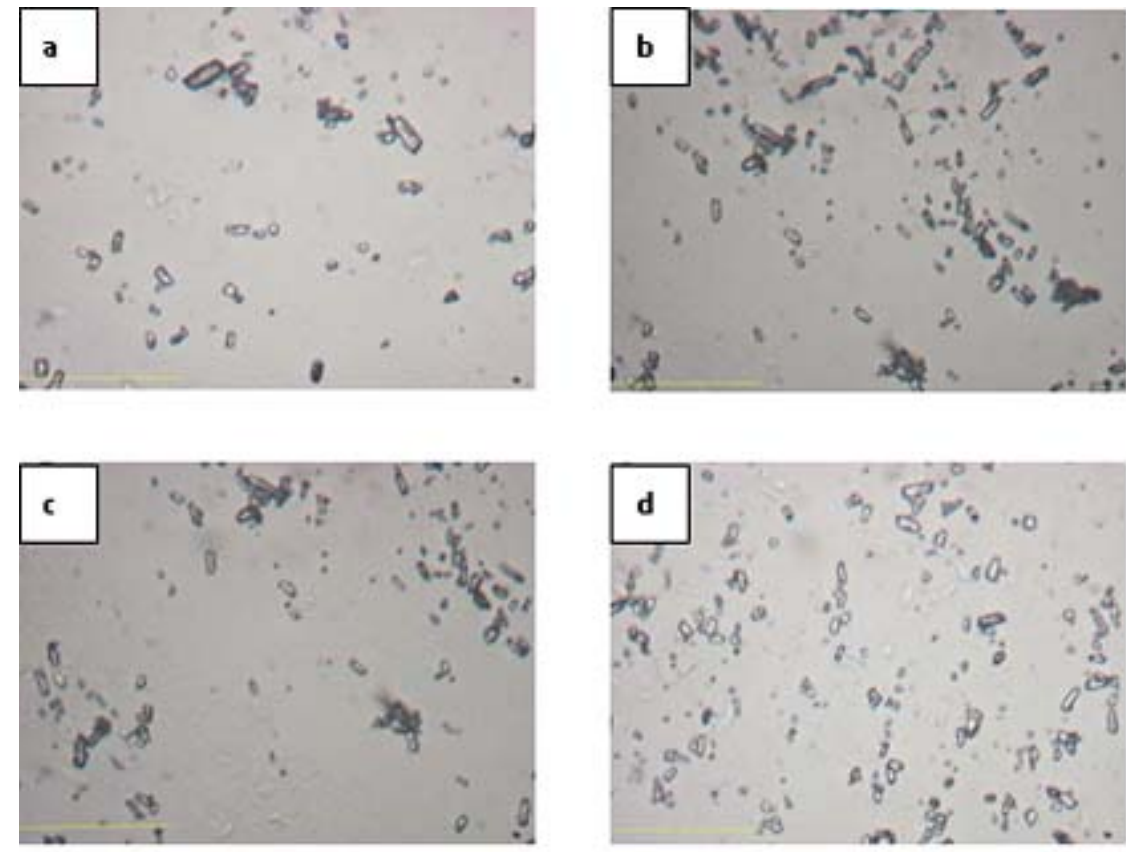

Fig. 8. Photographs (50 $\mu \mathrm{m}$ scale) of samples sonicated at: (a) 2 minutes, (b) 4 minutes,

(c) 6 minutes, (d) 8 minutes

Table 3. Analysis of crystals by image analysis software

\begin{tabular}{|c|c|c|c|c|}
\hline Sonication time [minutes] & $\begin{array}{c}\text { Average area } \\
{\left[\mu \mathrm{m}^{2}\right]}\end{array}$ & $\begin{array}{c}\text { Average } \\
\text { diameter }[\mu \mathrm{m}]\end{array}$ & $\begin{array}{c}\text { Average } \\
\text { roundness }\end{array}$ & $\begin{array}{c}\text { Elongation } \\
\text { ratio [-] }\end{array}$ \\
\hline $0^{*}$ & 14.78 & $4.02 \pm 1.66$ & 0.76 & 1.46 \\
\hline 2 & 10.44 & $3.64 \pm 1.27$ & 0.69 & 3.41 \\
\hline 4 & 8.90 & $3.36 \pm 1.06$ & 0.65 & 1.85 \\
\hline 6 & 6.23 & $2.81 \pm 1.18$ & 0.65 & 1.79 \\
\hline 8 & 5.93 & $2.74 \pm 0.52$ & 0.62 & 1.72 \\
\hline
\end{tabular}

*Patel and Murthy, 2009 


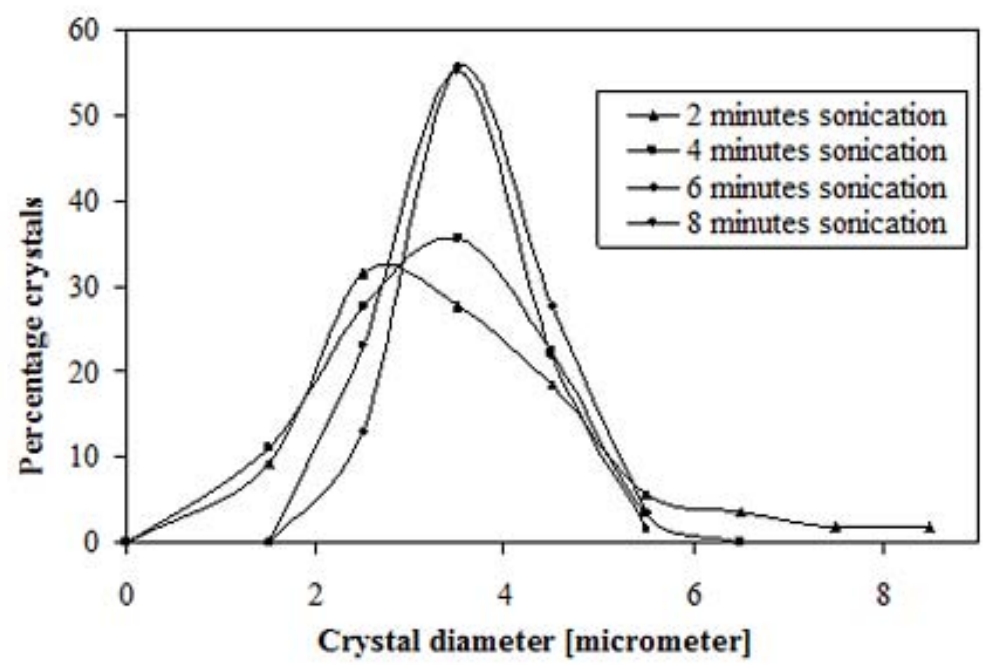

Fig. 9. Effect of sonication time on CSD

\section{CONCLUSIONS}

In the present work, lactose crystallisation from lactose solutions using ultrasound waves has been studied with and without protein with n-propanol. Protein content and $\mathrm{pH}$ of lactose solution were found to affect the lactose yield. Lactose yield was found to decrease for the sample sonicated in antisolvent n-propanol with an increase in the protein content. The yield of lactose in the presence of protein content was found to be $60-89 \%$ in 4 minutes of sonication. The morphology of lactose crystals was observed to have a rod/needle like shape. Continuous sonication decreased the crystal size of the samples sonicated with respect to an increase in time.

The authors acknowledge S. V. National Institute of Technology, Surat-395007, Gujarat, India, for financial support through Research and Development Project (A.P/R\&D/ChED/SP/2007-08).

\section{REFERENCES}

Azema N., 2006. Sedimentation behavior study by three optical methods - granulometric and electrophoresis measurements, dispersion optical analyzer. Powder Technol., 165, 133-139. DOI: 10.1016/j.powtec.2005.10.015

Bund R.K. Pandit A.B., 2007a. Sonocrystallisation: Effect on lactose recovery and crystal habit. Ultrason. Sonochem., 14, 143-152. DOI: 10.1016/j.ultsonch.2006.06.003.

Bund R.K., Pandit A.B., 2007b. Rapid lactose recovery from buffalo whey by use of antisolvent, ethanol. J. Food Eng., 82, 333-341. DOI: 10.1016/j.jfoodeng.2007.02. 045.

Chollangi A., Hossain M.Md., 2007. Separation of proteins and lactose from dairy wastewater, Chem. Eng. Process, 46, 398 - 404. DOI:10.1016/j.cep.2006.05.022.

Chow R., Blindt R., Chivers R., Povey M., 2003. The sonocrystallisation of ice in sucrose solutions: primary and secondary nucleation, Ultrasonics, 41, 595-604. DOI:10.1016/ j.ultras.2003.08.001.

De Castro M.D.L., Priego-Capote F., 2006. Analytical Application of Ultrasound, Elsevier, Amsterdam, The Netherlands, 143-192.

De Castro M.D.L., Priego-Capote F., 2007. Ultrasound - assisted crystallization (sonocrys-tallization). Ultrason. Sonochem., 14, 717-724. DOI: 10.1016/j.ultsonch.2006.12.004.

Dhumal R.S., Biradar S.V., Paradkar A.R., York P., 2009. Particle engineering using sonocrystallization: Salbutamol sulphate for pulmonary delivery. Int. J. Pharm., 368, 129-137. DOI:10.1016/j.ijpharm.2008.10.006. 
Dincer T.D., Parkinson G.M., Rohl A.L., Ogden M.I., 1999. Crystallization of $\alpha$-lactose monohydrate from dimethyl sufoxide (DMSO) solutions: influence of $\beta$-lactose. J. Cryst. Growth, 205, 368-374. DOI: 10.1016/S0022-0248(99)00238-9.

Fernando M., Agustın O, Elena I., Tiziana F., 2007. Modeling solubilities of sugars in alcohols based on original experimental data. AIChE J., 53, 2411-2418. DOI: 10.1002/ aic.

Gogate P.R., Tayal R.K., Pandit A.B., 2006. Cavitation: a technology on the horizon. Curr. Sci. - India, 91, 35-46.

Jayani C., Bogdan Z., Martin P., Sandra K., Muthupandian A., 2011. Effects of ultrasound on the thermal and structural characteristics of proteins in reconstituted whey protein concentrate. Ultrason. Sonochem., 18, 951957. DOI:10.1016/j.ultsonch.2010.12.016.

Leviton A., 1949. Methanol extraction of lactose and soluble proteins from skim milk powder. Ind. Eng. Chem., 41, 1351-1357. DOI: 10.1021/ie50475a013.

Mullin J.W., 2001. Crystallization. $4^{\text {th }}$ edition, Butterworth-Heinemann, New Delhi, 32-85.

Patel S.R., Murthy Z.V.P., 2009. Ultrasound assisted crystallization for the recovery of lactose in an anti-solvent acetone. Cryst. Res. Technol., 44, 889-896. DOI: 10.1002/ crat.200900227.

Patil M.N., Gore G.M., Pandit A.B., 2008. Ultrasonically controlled particle size distribution of explosives: a safe method. Ultrason. Sonochem., 15, 177-187. DOI: 10.1016/ j.ultsonch.2007.03.011.

Received 02 September 2011

Received in revised form 12 December 2011

Accepted 16 December 2011 